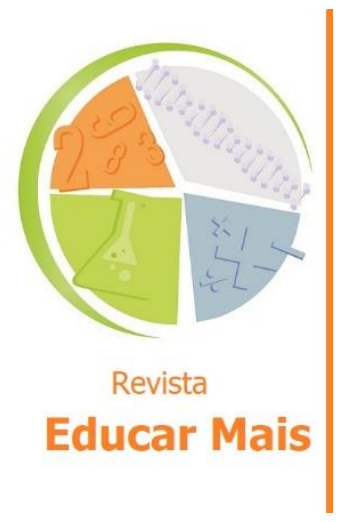

\section{Experimentos físicos na aula de matemática: reflexões sobre um Ateliê de Matemática no Ensino Fundamental}

\section{Physical experiments in the mathematics class: reflections about an Atelie of Mathematics Studio in fundamental teaching}

Rodrigo Sychocki da Silva ${ }^{1}$; Leandro de Andrades Campos ${ }^{1}$

\title{
RESUMO
}

O presente artigo emerge como um produto teórico e reflexivo de uma pesquisa feita para uma dissertação de mestrado em Ensino de Matemática, que consistiu no desenvolvimento de atividades teóricas e experimentais de caráter interdisciplinar, a partir de estruturação teórica e metodológica seguida da experimentação nas aulas de matemática em uma turma dos anos finais do Ensino Fundamental. Tais atividades tiveram o propósito de observar a evolução do aprendizado dos estudantes de uma turma de nono ano de uma escola municipal, situada na cidade de Canoas no estado do Rio Grande do Sul. O objetivo do presente artigo é produzir e apresentar reflexões em relação à elaboração de conceitos matemáticos construídos em sala de aula durante a realização de experimentos físicos, mediadas pela ação do professor. Estrutura-se o estudo a partir da perspectiva metodológica qualitativa, mais especificamente com as características de uma pesquisa-ação, onde as análises e reflexões se debruçam desde a realização das atividades até as análises dos dados obtidos na pesquisa. A título de contribuição do estudo apresenta-se a proposta de ensino organizada na forma de um ateliê de matemática, sendo este um espaço para diálogo e construção de ideias matemáticas.

Palavras-chave: Ateliê de Matemática; Experimentos físicos; Interdisciplinaridade.

\begin{abstract}
This paper emerges as a theoretical and reflective product of a research done for a Master's dissertation in Mathematics Teaching, which consisted of the development of theoretical and experimental activities of interdisciplinary character, based on theoretical and methodological structuring followed by experimentation in mathematics classes in a class in the final years of elementary school. These activities had the purpose of observing the evolution of the learning of the students of a class of ninth grade of a municipal school, located in the city of Canoas in the state of Rio Grande do Sul. The aim of this article is to produce and present reflections on the elaboration of mathematical concepts built in the classroom during physical experiments, mediated by the teacher's action. The study is structured from the qualitative methodological perspective, more specifically with the characteristics of an action research, where the analyzes and reflections focus on the performance of activities to the analysis of data obtained in the research. As a contribution of the study is presented the teaching proposal organized in the form of a mathematics studio, which is a space for dialogue and construction of mathematical ideas.
\end{abstract}

Keywords: Atelie of Mathematics; Physical experiments; Interdisciplinarity.

\footnotetext{
${ }^{1}$ UFRGS - Universidade Federal do Rio Grande do Sul - Porto Alegre/RS - Brasil.
} 


\section{INTRODUÇÃO}

O presente texto é o recorte de uma pesquisa de mestrado, Campos (2019), em Ensino de Matemática, lança luz à temática da construção e realização de uma prática de ensino que envolve um ateliê de matemática no ensino fundamental. Durante a pesquisa usou-se o termo "ateliê" na caracterização do espaço pedagógico construído a partir da ação de todos os partícipes do processo educativo: estudantes e professor.

O desafio de realizar atividades de caráter experimental e interdisciplinar nas aulas de matemática emerge, em um período anterior à realização do curso de mestrado, durante uma reflexão em que um dos autores do presente texto e professor da turma na ocasião, ministrava um momento de discussão sobre problemas envolvendo o Movimento Retilíneo Uniforme (MRU). Os estudantes na ocasião manifestaram interesse e puderam, em uma aula de matemática, discutir e refletir sobre a matemática necessária para a compreensão e construção das ideias físicas.

Diante disso, iniciou-se um processo de reflexão sobre como a interdisciplinaridade poderia contribuir na compreensão dos conteúdos abordados nas aulas de matemática. Nesse sentido encontramos amparo em Almeida (2004, p.11), que afirma ser necessária uma contextualização aos problemas estudados, pois é "uma estratégia para encontrar os elos que permitem ao aluno dar significado ao que está aprendendo, o que depende em grande parte da sensibilidade do professor".

Assim, o estudo da matemática com predomínio de ênfase a técnicas de cálculo descontextualizado, com frequência costuma não fazer sentido aos estudantes que acabam por esmorecer de estudá-la, uma vez que não conseguem perceber utilidade em seu cotidiano. Também nesse sentido, a Base Nacional Curricular para o Ensino Fundamental (BRASIL, 2018, p.14-15) propõe que o ensino não seja fragmentado, mas que deva ser um ensino comprometido com a formação global dos estudantes como, por exemplo, intelectual, física, afetiva, social, moral e simbólica. Ou seja, o estudante deve não somente aprender conteúdos de matemática, português, geografia, história, ciências, arte, entre outras disciplinas, mas também deve ter condições de relacionar estes, construindo uma consciência crítica e ampliando a sua visão de mundo.

A pesquisa de mestrado realizada, de caráter metodológico qualitativo, almejou construir e executar uma prática de ensino que envolvesse os estudantes participantes em experimentos e momentos de construção do conhecimento matemático. No presente artigo apresenta-se um recorte do referencial teórico estudado, e que sustentou a proposta de construção e análise das atividades, de caráter teórico e prático. Após isso, mostra-se no presente texto a caracterização metodológica, bem como os materiais e métodos utilizados durante a coleta de dados. Em seguida expõem-se, com uma análise, os achados na pesquisa. Para encerrar, a título de considerações finais, explana-se sobre o potencial pedagógico ancorado em práticas de ensino que tornam o estudante o protagonista a partir da ação pedagógica do professor.

\section{FUNDAMENTAÇÃO TEÓRICA: APORTE SOBRE INTERDISCIPLINARIDADE E AÇÃO DOCENTE}

Desde a antiguidade o homem construiu questionamentos que o levaram a pensar, com intuito de buscar respostas sobre os mais diversos assuntos como, por exemplo, o surgimento do universo, de sua própria espécie, sobre formato da terra e a distância entre os planetas. Os questionamentos foram 
a motivação necessária que "empurrou" o homem em busca/construção de respostas e, com elas, consequentemente houve o avanço científico e tecnológico que se conhece atualmente. Dessa forma, a curiosidade do indivíduo mostra-se como um possível aliado aos professores em sala de aula e ao próprio indivíduo, com vistas à evolução do seu conhecimento.

Tal curiosidade bem como os questionamentos também são presentes em estudantes de ensino fundamental, em relação ao que está sendo ensinado e quais aplicações existem para os conhecimentos debatidos. Entende-se dessa forma que os questionamentos, bem como a curiosidade dos estudantes, podem ser fatores favoráveis ao processo de descobertas e de construção do conhecimento deles.

Dessa forma, os questionamentos dos estudantes em relação à utilidade de assuntos abordados no ambiente escolar e em sua vida fora da escola, devem ser considerados como uma característica pertencente à natureza curiosa e descobridora do homem. Assim, como o homem buscou desde os primórdios de sua história respostas para os enigmas do universo, também os estudantes procuram um sentido para o que estão estudando. De modo que entende-se serem pertinentes tais questionamentos por parte deles, o qual deve ser tomado como um alerta para que o ensino não se torne o que para Japiassu (1976, p. 14) é um sintoma "mórbido de regressão" da ciência, a saber:

Quanto mais se desenvolvem as disciplinas do conhecimento, diversificando-se, mais elas perdem o contato com a realidade humana. Nesse sentido, podemos falar de uma alienação do humano, prisioneiro de um discurso tanto mais rigoroso quanto mais bem separado da realidade global, pronunciando-se num esplendido isolamento à ordem das realidades humanas. (JAPIASSU, 1976, p. 14)

Dito isto, entende-se ser necessário estabelecer estratégias de ensino, ou seja, criar situações que motivem, envolvam e agucem a curiosidade pela descoberta dos estudantes. Mais ainda, situações em que os estudantes sejam convidados a explorar e refletir, enfim, sejam corresponsáveis pelo processo de aprendizado. O que por vezes ocorre, ao contrário, a compreensão por parte dos estudantes e a resolução dos problemas dependem, exclusivamente da interpretação de enunciados e da utilização de equações. Sobre isso, Piaget (2011, p. 22) reflete relacionando com as dificuldades inerentes ao processo de aprendizagem:

São as "lições" oferecidas que lhes escapam à compreensão, e não a matéria. É sobretudo possível - e nós o verificamos em diversos casos - que o insucesso escolar em tal ou tal ponto decorra de uma passagem demasiado rápida da estrutura qualitativa dos problemas (por simples raciocínios lógicos, mas sem a introdução imediata das relações numéricas e das leis métricas) para a esquematização quantitativa ou matemática (no sentido das equações já elaboradas) usada habitualmente pelo físico. Nesse particular, admitiríamos sem dúvida algumas aptidões diferenciais que opõem os espíritos estritamente dedutivos (a partir de determinada idade) aos experimentais e concretos; todavia, mesmo no campo da matemática, muitos dos fracassos escolares se devem àquela passagem muito rápida do qualitativo (lógico) para o quantitativo (numérico).

De acordo com a citação acima, a pesquisa aqui apresentada valorizou os aspectos qualitativos reservando mais tempo a estes, antes de introduzir equações ou leis que generalizam fenômenos observados nos mais diversos problemas existentes do cotidiano dos estudantes, ou nas demais disciplinas escolares. Além disso, pretendeu-se incentivar nos estudantes os métodos ativos, os quais estimulam a atividade pesquisadora, com o intuito de que fossem percebidas certas regularidades em problemas dados e, a partir disso, pudessem construir suas próprias conclusões. Segundo Piaget 
(2011, p. 23), os métodos ativos têm como característica conferir "[...] especial relevo à pesquisa espontânea da criança ou do adolescente e exigindo-se que toda verdade a ser adquirida seja reinventada pelo aluno, ou pelo menos reconstruída, e não simplesmente transmitida $[\ldots]$...

Segundo o referido teórico (Piaget e Braga, 2011, p. 24), o fato de incentivar a pesquisa espontânea dos estudantes não significa, obviamente, deixar os mesmos totalmente livres para fazerem o que quiserem. Pelo contrário, na verdade o que se deseja é que "[...] o professor deixe de ser apenas um conferencista e que passe a estimular a pesquisa e o esforço, em vez de se contentar com a transmissão de soluções já prontas [...]".

No intuito de valorizar os aspectos qualitativos do processo, a ação dos estudantes durante as aulas, e de oportunizar mais questionamentos do que respostas prontas, estendeu-se o convite à investigação para a turma a partir de experimentos físicos. Entende-se que o uso de experimentos nas aulas de matemática é uma forma de propor a ação de observação dos estudantes, tanto em relação a aspectos físicos quanto a matemáticos. Também é uma forma de romper com a fragmentação disciplinar existente entre as especialidades de matemática e física.

É nesse sentido que a Base Nacional Curricular para o Ensino Fundamental (BRASIL 2018, p. 14-15) apresenta que o ensino não seja fragmentado, mas que deva ser comprometido com a formação global dos estudantes. Com isso, o estudante deve não somente aprender conteúdos específicos de cada disciplina, mas também deve ter condições de relacioná-los, formando dessa maneira uma consciência crítica e ampliando a sua visão de mundo. Assim, sugere que os professores estabeleçam estratégias para:

Contextualizar os conteúdos dos componentes curriculares, identificando estratégias para apresentá-los, representá-los, exemplificá-los, conectá-los e torná-los significativos, com base na realidade do lugar e do tempo nos quais as aprendizagens estão situadas. (BRASIL, 2018, p. 16)

Em contrapartida, o estudo descontextualizado da matemática, na qual o professor apresenta a mesma como um produto pronto e acabado, exclui a possibilidade de o estudante desenvolver autonomia e liberdade sobre quais caminhos trilhar na construção de soluções do seu próprio conhecimento. De acordo com D'Ambrósio (1989, p. 16), quando os professores propõem este modelo de aula, os estudantes "[...] passam a acreditar que o seu papel na aula de matemática é passivo e desinteressante [...]" haja vista que ao "[...] aluno não é dado, em nenhum momento, a oportunidade ou gerada a necessidade de criar nada, nem mesmo uma solução mais interessante [...]".

Em oposição a esse modelo de aula, que engessa a iniciativa e a criatividade dos estudantes, optouse em realizar experimentos físicos nas aulas de matemática. Ao propor experimentos para a investigação dos estudantes, o professor não consegue prever todos os caminhos que eles irão trilhar, sendo esta uma aula "não previsível". Desse modo o professor deixa de ser aquele que tem o "controle" da aula para se tornar, junto aos estudantes, um pesquisador e aquele que auxilia a ação destes. Fazenda (1994, p. 38) ilustra a relação advinda em sala de aula com um exemplo, em que o "[...] preceptor é aquele que ajuda o discípulo a fazer uma leitura das coisas próprias do conhecimento em geral $[\ldots]$ " e o discípulo é aquele que "[...] gradativamente é indicado a ampliar essa leitura [...]".

Na realização da pesquisa entendeu-se como necessário aos estudantes estabelecer conexões com outros conhecimentos científicos para que houvesse uma motivação em aprendê-los e, que assim os estudantes pudessem realizar uma melhor leitura do mundo ao seu redor. De acordo com Pietrocola 
(2002, p. 89), a relação existente entre matemática e física é complexa e faz da matemática um estruturante do conhecimento físico, de modo que a primeira pode acarretar profundas implicações para o ensino da segunda. De acordo com ele:

Na comparação entre estas culturas, a linguagem utilizada é também uma fonte de diferenciação importante, pois, ao contrário do que ocorre no cotidiano, a ciência, normalmente, vale-se da Matemática como forma de expressar seu pensamento. Seu emprego torna-se critério de cientificidade, na física, na medida em que a incapacidade de expressar propriedades de sistemas em linguagem matemática inviabiliza mesmo a possibilidade de admiti-las como hipóteses para o debate científico. (PIETROCOLA, 2002, p. 89-90)

A partir da citação acima, observa-se que sem conhecimentos matemáticos a produção de conhecimentos da física se torna uma tarefa difícil, uma vez que ao abrir os livros de física percebese a dependência da utilização da linguagem matemática, com o fim de expressar resultados e discutir o conhecimento científico em todos os níveis de escolaridade. Para Pietrocola $(2002$, p. 90) não há dúvidas da necessidade de se ensinar matemática, pelo contrário, segundo ele:

[...] para fazermos Física, temos que conhecer Matemática. E, portanto, temos que ensiná-la! Porém, a questão colocada desta forma mascara o problema de saber como a Matemática deve ser ensinada e, portanto, aprendida no contexto da Física [...]. (PIETROCOLA, 2002, p. 90)

Ou seja, nota-se a importância do ensino de matemática como fator estruturante ao ensino de física. De acordo com o autor acima citado, outra barreira que os estudantes têm que ultrapassar é um ensino da matemática sem justificativa, o que acaba por diminuir o interesse de estudo. E que mostrar o papel da matemática no ensino da física pode ser um fator motivador, para diminuir o desinteresse dos estudantes em um ensino em que não se pode identificar pertinência (PIETROCOLA, 2002, p. 91).

A partir do exposto, vale mencionar dois posicionamentos, o primeiro aos professores, sobre o ensino de matemática e o modo que os estudantes a utilizam para criar sua própria leitura de mundo. 0 segundo, direcionado aos estudantes, sobre a pertinência do estudo da matemática. Uma das justificativas apresentadas pelo autor para a pertinência de tal estudo é a de que aprendemos a entender as leis físicas expressas em linguagem matemática. De acordo com Paty (1989 apud Pietrocola 2002, p. 93), para Galileu a "Matemática era concebida como um conhecimento que permitia uma leitura direta da natureza, da qual, precisamente, era a língua".

Assim sendo, para a realização dessas leituras de mundo é necessário que cientistas, professores e estudantes desenvolvam a habilidade de transitar entre as diferentes linguagens. Ou seja, a partir de observações da natureza deve-se ter a habilidade de relatar, por meio de expressões matemáticas, determinados fenômenos. Além disso, de acordo com Pietrocola (2002, p. 95), tal habilidade faz referência à produção do método científico, no qual é necessário que o indivíduo passe do qualitativo ao quantitativo e, para isso, seria preciso "[...] valer-se de técnicas especiais, presentes na observação, na experimentação e na descrição matemática precisa [...]". Além disso, o autor expõe que:

A minha experiência como professor de Física do Ensino Médio e universitário tem me mostrado que não basta ao aluno conhecer a Matemática no seu campo próprio de validade para obter um bom desempenho em Física. Isto é, não é suficiente conhecêla enquanto "ferramenta" para poder utilizá-la como estruturante das idéias físicas 
sobre o mundo. Este fato parece exemplificar a conclusão extraída da análise epistemológica realizado anteriormente. Ao concebermos a apreensão do real como fruto de um processo de interação dialética entre abstrato e concreto, entre teórico e empírico, não há como evitar o tratamento da Matemática como elemento que participa, com sua especificidade própria, do contexto da construção do conhecimento. Assim, um dos atributos essenciais ao educador com relação a esta questão é perceber que não se trata apenas de saber Matemática para poder operar as teorias Físicas que representam a realidade, mas de saber apreender teoricamente o real através de uma estruturação matemática. (PIETROCOLA, 2002, p. 106)

A posição de Pietrocola (2002) é considerar que se trata de um equívoco a noção de que basta que os estudantes tenham uma boa base matemática para que compreendam conceitos de física e tenham êxito na mesma. Antes, é necessário que os estudantes consigam representar o real por meio das estruturas matemáticas, ou nas palavras dele conforme a citação anterior, "apreender teoricamente o real através de uma estruturação matemática". Nesse sentido, a matemática seria uma ferramenta do método empírico, pela qual o cientista, o professor e o estudante poderiam representar e conceituar os fatos observados na natureza.

A partir disso, percebe-se como a disciplina de matemática está ligada à disciplina de física. Porém, essa relação, que deveria ser de contribuição e de parceria entre as disciplinas, por vezes, de acordo com o autor em estudo, torna-se um jogo de "empurra - empurra". Sobre isso é explanado que:

Na organização curricular do Ensino Médio, há uma estrutura de pré-requisitos que faz com que os conteúdos presentes numa disciplina articulem-se com aqueles presentes em outras. Na Física, a relação com a Matemática é sintomática, e se coloca como um quebra-cabeça de difícil solução. Os professores de Física gostariam que seus alunos chegassem à sala de aula com os pré-requisitos matemáticos completos. Em contrapartida, os professores de Matemática não aceitam, com razão, que sua disciplina seja pensada apenas como instrumento para outras disciplinas, impondo uma programação que nem sempre se articula com aquela da Física. (PIETROCOLA, 2002, p. 91)

A citação acima demonstra que a articulação entre as disciplinas de física e matemática não é uma tarefa simples, e por isso é descrita como um "quebra-cabeça" de difícil solução. Assim, é válido mencionar que o presente trabalho de pesquisa não tem a pretensão de solucionar os problemas do ensino de matemática e física, mas sugerir não um ensino de matemática cujo fim seja a "aplicação" na disciplina de física. Almejou-se propor situações em que os estudantes pudessem construir conceitos de matemática a partir da observação de fenômenos da física. Ou seja, esperava-se que tais atividades contribuíssem no desenvolvimento da habilidade da descrição matemática da realidade, sua interpretação, culminando na generalização de determinados aspectos matemáticos observados nos experimentos, os quais poderão ser reaplicados em problemas posteriores.

O contexto dos movimentos de móveis (cinemática) possibilita relacionar a matemática e a física, uma vez que para a representação desses movimentos é utilizado, com frequência, o conceito de função, seja por meio de tabelas, diagramas, gráficos ou expressões matemáticas (álgebra). Ou seja, é necessário que o indivíduo consiga estabelecer relações entre essas diferentes formas de representação das funções. De acordo com Lopes (2003, p. 2), por vezes, o que se percebe nos estudantes é justamente a falta dessa habilidade de compreender e de estabelecer relações entre as diversas áreas de aplicação do conceito em questão. Sobre isso, é possível refletir que:

Dentre estas está a inabilidade de construir conexões entre as diferentes representações de funções: fórmulas, tabelas, diagramas, gráficos, expressão verbal 
das relações, e, ainda, em estabelecer interações com outras áreas do conhecimento que fazem uso dessas mesmas representações, situadas em contextos diferentes. Outra dificuldade apresentada está ligada à complexidade na construção do próprio conceito de função e, nesse sentido, é imprescindível ter clareza de que a aprendizagem desse conceito é um processo lento, evolutivo e gradual. E requer, portanto, um espaço que propicie a construção, individual e coletiva, não só desse conceito como dos conhecimentos adjacentes a ele e das relações em domínios intra e interdisciplinares que proporciona. Neste processo não existem receitas, mas sim questionamentos, indagações e dúvidas. (LOPES, 2003, p. 2)

O desafio que os educadores têm nesse sentido é o de propor espaços nos quais os aprendizes possam construir os conceitos relativos ao tema e, ao mesmo tempo, produzir significado a eles. Além disso, esse espaço deve proporcionar ao estudante a emancipação dele no processo de sua aprendizagem, e também produzir significado à matemática aprendida. A partir da leitura e entendimento de referenciais teóricos, que apontavam para um ensino que oportunizasse a construção de significado aos conteúdos pelos estudantes, é que foram realizados nas aulas de matemática experimentos físicos, os quais serão apresentados e debatidos adiante.

\section{APORTES METODOLÓGICOS: CARACTERIZAÇÃO, MATERIAL E MÉTODOS}

Buscou-se apoio teórico em D'Ambrosio (2004, p. 12), o qual afirma que pesquisas qualitativas têm como foco "[...] entender e interpretar dados e discursos, mesmo quando envolve grupos de participantes [...]". E ainda, para D'Ambrosio (2004, p. 21), a pesquisa qualitativa "[...] é o caminho para escapar da mesmice. Lida e dá atenção às pessoas e às suas ideias, procura fazer sentido de discursos e narrativas que estariam silenciosas. E a análise dos resultados permitirá propor os próximos passos [...]". Assim, justifica-se a escolha por tal metodologia pelo fato que seja de nosso interesse entender como se dá a construção de conceitos matemáticos por meio das práticas que serão propostas, as posições particulares de cada estudante sejam elas por meio de diálogos entre os pares ou por meio de desenvolvimentos escritos (análise documental). Ou seja, não estamos interessados apenas nos resultados, mas também no caminho percorrido pelos estudantes para construírem tais resultados. Tais aspectos estão de acordo com a caracterização de pesquisa qualitativa trazida por Bogdan e Biklen (1994, apud Borba e Araújo, 2004, p. 25):

1. Na pesquisa qualitativa a fonte direta de dados é o ambiente natural, constituindo o investigador o instrumento principal (p.47);

2. A investigação qualitativa é descritiva (p.48);

3. Os investigadores qualitativos interessam-se mais pelo processo do que simplesmente pelos resultados ou produtos (p.49);

4. Os investigadores qualitativos tendem a analisar os seus dados de forma indutiva (p. 50);

5. O significado é de importância vital na abordagem qualitativa (p. 50).

Além disso, na pesquisa qualitativa, o professor-pesquisador insere-se como pesquisador da sua própria prática e cujo intuito não é somente observar, mas também intervir na prática com o propósito de desbravar por caminhos que aperfeiçoem a mesma. Dessa forma, entende-se que a postura enquanto professor-pesquisador caracteriza um tipo especial de pesquisa participante a qual é denominada por Fiorentini (2006) como pesquisa-ação e definida da seguinte maneira:

A pesquisa-ação, nesse sentido, é um processo investigativo de intervenção em que caminham juntas prática investigativa, prática reflexiva e prática educativa. Ou seja, 
a prática educativa, ao ser investigada, produz compreensões e orientações que são imediatamente utilizadas na transformação dessa mesma prática, gerando novas situações de investigação. (FIORENTINI, 2006, p. 77)

Assim, usando-se como referência da pesquisa a definição proposta por Fiorentini (2006, p. 113), torna-se elemento importante para se alcançar os objetivos propostos pela pesquisa a utilização de uma sequência de etapas que, de certa forma, definem a pesquisa-ação. Tal sequência é ilustrada e descrita por Fiorentini por meio do esquema a seguir:

Figura 1: Ciclos sucessivos da Pesquisa Ação

Planejamento $\Rightarrow \mathrm{A}$ ção $\Rightarrow$ Observação $\Rightarrow$ Registros $\Rightarrow$ Sistematização/Reflexão/Análise $\Rightarrow$ Avaliação

$\Rightarrow$ Planejamento de novas ações $\Rightarrow$ Novas ações $\Rightarrow$ Novas observações $\Rightarrow$ Novos registros $\Rightarrow$ Novas

análises e avaliações $\Rightarrow$ e assim por diante

Fonte: Fiorentini (2006, p. 113)

A partir da sequência acima é possível entender a pesquisa-ação como um processo em que o investigador observa, reflete sobre ela e, por fim, intervém com o intuito de proporcionar o aperfeiçoamento do aprendizado dos estudantes. Em outras palavras, tal pesquisa está centrada na reflexão-ação. De acordo com Fiorentini (2006, p. 77), na pesquisa-ação a "[...] prática educativa, ao ser investigada produz compreensões e orientações que são imediatamente utilizadas na transformação dessa mesma prática, gerando novas situações dessa mesma investigação [...]". Nesse sentido, as ações em sala de aula buscaram potencializar e valorizar o diálogo, a construção coletiva de conceitos matemáticos por meio de debates, além da construção de significados daquilo que estiver sendo estudado e investigado.

O conjunto de atividades, que resultou em 15 dias de trabalho em sala de aula, foi elaborado durante o estágio supervisionado do Mestrado Profissional e foi aplicada em uma turma de nono ano da Escola Municipal de Ensino Fundamental General Osório, da cidade de Canoas (RS). A turma era composta por 32 estudantes, predominantemente moradores do bairro Rio Branco da cidade de Canoas. No decorrer das atividades não houve problemas que interferissem de forma negativa no andamento da proposta de ensino, pelo contrário, de um modo geral a turma de estudantes mostrou-se participativa e engajada durante todo o desenvolvimento das atividades.

Com o intuito de não se perder algum detalhe importante em relação aos caminhos trilhados pelos estudantes na construção de soluções, optou-se por registrar a dinâmica das aulas por meio de gravações de áudio e vídeo, diário de campo, bem como os registros realizados pelos estudantes. Entende-se ser de fundamental importância tais registros já que durante as investigações realizadas pelos estudantes, por vezes, perdem-se aspectos da forma de pensar e de agir dos mesmos. Assim, de posse desse material, pode ser feita posteriormente uma análise e reflexão a partir do material coletado.

\section{APRESENTAÇÃO E REFLEXÃO A PARTIR DOS EXPERIMENTOS}

Os experimentos aqui apresentados fizeram parte de uma proposta pedagógica maior, e que pode ser encontrada de forma completa na dissertação de Campos (2019). O presente texto apresenta e disserta sobre o uso de dois experimentos físicos nas aulas de matemática, os quais possibilitam a reflexão e construção de conhecimentos por parte dos estudantes. 
Experimento 1 (enchimento de uma coluna com água): O primeiro experimento consistiu na observação do crescimento de uma coluna de água enchida com vazão constante. Nesse experimento os estudantes deveriam observar o crescimento de uma coluna de água, e realizar anotações referentes aos tempos em que a coluna atingia determinadas marcas do tubo acrílico. Foi sugerido aos estudantes que gravassem por meio de vídeo o experimento para que, em seguida, pudessem retirar dos vídeos os tempos em que a coluna atingisse determinadas marcas. A turma preferiu cronometrar e marcar os tempos relativos às marcas do tubo.

O experimento foi realizado cinco vezes com diferentes velocidades de vazão de água. Considerando que, uma vez aberta a torneira a uma velocidade constante de vazão da água, esperava-se de fato a construção de um gráfico de uma função caracterizada por uma reta. Porém, não foram indicadas aos estudantes as características da construção dos gráficos que possivelmente surgiriam por intermédio desse experimento, uma vez que o experimento em questão estava sujeito as observações realizadas pelos estudantes, ou seja, o ponto de vista de cada um.

Nossa expectativa era de que os estudantes realizassem a plotagem de pares ordenados no plano cartesiano e percebessem características peculiares de cada experimento, daí também o motivo de realizarmos o experimento com velocidades de vazões diferentes. Um dos aspectos peculiares de cada gráfico que esperávamos ser percebida pelos estudantes era a relação existente entre a inclinação do gráfico e a velocidade de crescimento de determinado fenômeno, neste caso, a coluna de água. Um dos primeiros tópicos que questionamos os estudantes foi sobre o porquê de utilizarmos apenas o primeiro quadrante do plano cartesiano para representar os gráficos dos experimentos. Ao que responderam da seguinte maneira.

\section{- Porque não existem tempo nem comprimento negativos.}

Uma das dificuldades que os estudantes encontraram, e que obstaculizou eles o reconhecimento de características peculiares de cada experimento e, consequentemente, de cada gráfico, foi o de manter uma coerência nos espaços entre cada ponto no plano cartesiano. Ou seja, uma vez adotada uma distância na malha quadriculada para determinado valor de comprimento ou de tempo, tal distância deve servir de parâmetro para os demais pontos do plano cartesiano.

Nosso entendimento é que a prática envolvendo a construção de gráficos por meio dos experimentos nas aulas de matemática sob a mediação do professor-pesquisador, um dos autores desse texto, contribuiu no aprendizado dos estudantes, uma vez que proporcionou que eles cometessem os erros e, consequentemente, proporcionou momentos de discussões sobre esses, resultando assim em esclarecimento e aprendizado. Ou seja, os erros cometidos foram parte importante do processo de aprendizado e que possivelmente seria minimizada ou ignorada em aulas em que não exista espaço para a construção de relações entre valores, tentativa de resolução por parte deles, criatividade, nem tampouco erros. Nosso entendimento é de que o erro do estudante se apresenta e faz parte do processo de aprendizado. A seguir, utilizamos o gráfico dos estudantes B.D. e N.L. para realização de debates e investigação com os estudantes. 
Figura 2: Gráfico construído pelos estudantes B.D. e N.L

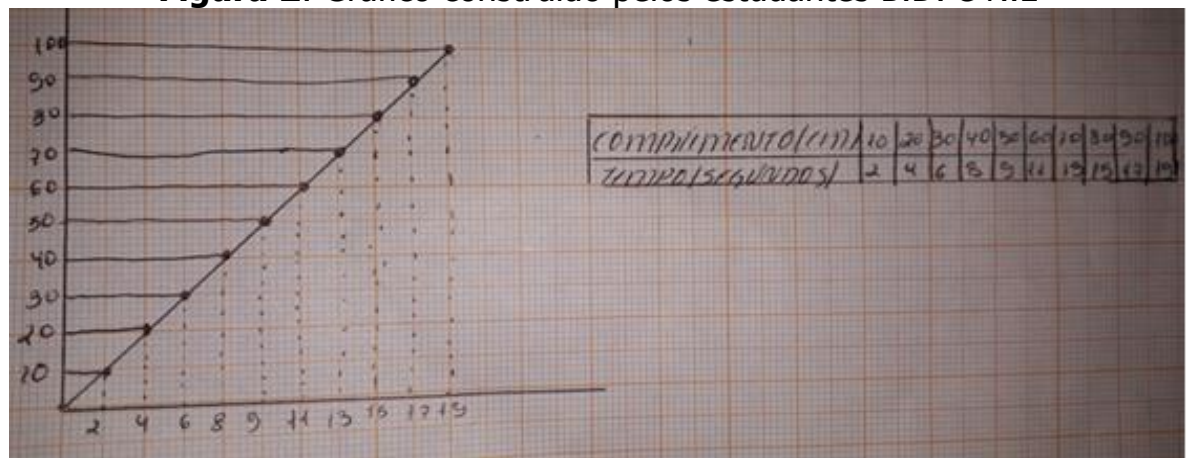

Fonte: acervo do pesquisador

- Professor: como sabemos, realizamos o experimento com o tubo d'água em que tínhamos marcas de 10 em 10 centímetros no tubo, além disso, tínhamos que anotar o tempo em que a coluna atingia essas marcas, ou seja, anotar os pares ordenados.

- Professor: Nesse experimento vimos que o gráfico dessa função é contínuo, já que o comprimento da coluna d'água não pula de 10 em 10 centímetros, nem tampouco o tempo pula de 2 em 2 segundos ou de 3 em 3 segundos.

- Professor: Mas o que quero chamar a atenção é para o fato de que se eu adotar uma distância no plano cartesiano como no gráfico acima, foi adotado para 2 um "espacinho" do plano cartesiano, para a metade desse espacinho vai ser?

- Aluna A.M.: um.

- Professor: e pra metade da metade?

- Aluna N.0.: 0,5.

- Professor: e pra metade da metade da metade?

- Aluna N.0.: 0,25.

- Professor: e pra metade da metade da metade da metade? 0,125.

Após os debates descritos acima e mais as análises de outros grupos, os estudantes chegaram à conclusão de que o gráfico construído pelos colegas se mostrou coerente em se tratando de valores estabelecidos para tempo e comprimento da coluna de água nos eixos coordenados.

Figura 3: Gráfico construído pelas estudantes N.A., M.P. e B.M

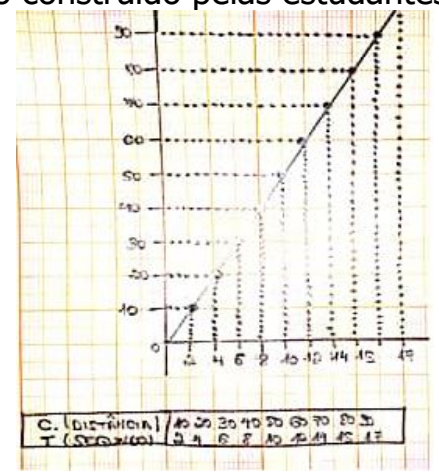

Fonte: acervo do pesquisador 
Ainda nessa aula, salientamos aos estudantes que havendo coerência entre os valores adotados para tempo e comprimento nos eixos coordenados, poder-se-ia arredondar valores de tempo, uma vez que em se tratar de observações há registros de décimos e centésimos de segundos, conforme mostrado na figura 4 a seguir:

Figura 4: Tempos cronometrados pelos estudantes durante a prática

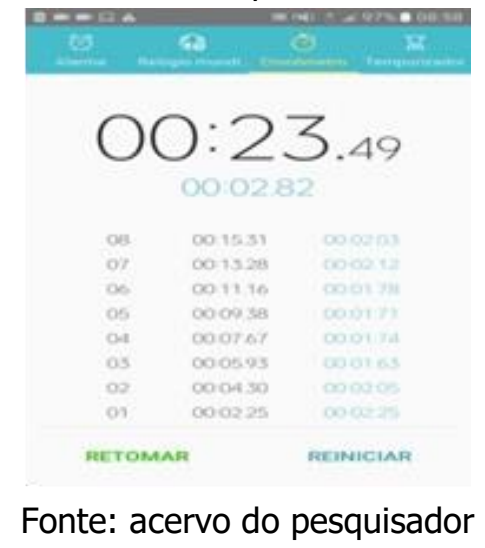

Esse experimento foi cronometrado pelos estudantes e seus dados foram expostos no quadro para os demais colegas, uma forma de organização dos estudantes. Acreditamos que a escolha por essa forma de organização se deu em razão de os estudantes perceberem que a maneira de organização em experimentos anteriores, em que vários estudantes cronometraram e compartilharam em redes sociais, se mostrou um tanto confusa. Já que ao realizarmos mais de um experimento por aula, por vezes, os dados se confundiam entre os experimentos e não se tinha garantia de que todos os estudantes teriam acesso aos dados.

O desenvolvimento dessa atividade proporcionou aos estudantes compreenderem aspectos importantes na leitura e interpretação de gráficos, uma vez que foi estabelecida relação entre a velocidade de crescimento e a inclinação do gráfico. Na figura 5 mostramos um dos gráficos construídos pela estudante A.M..

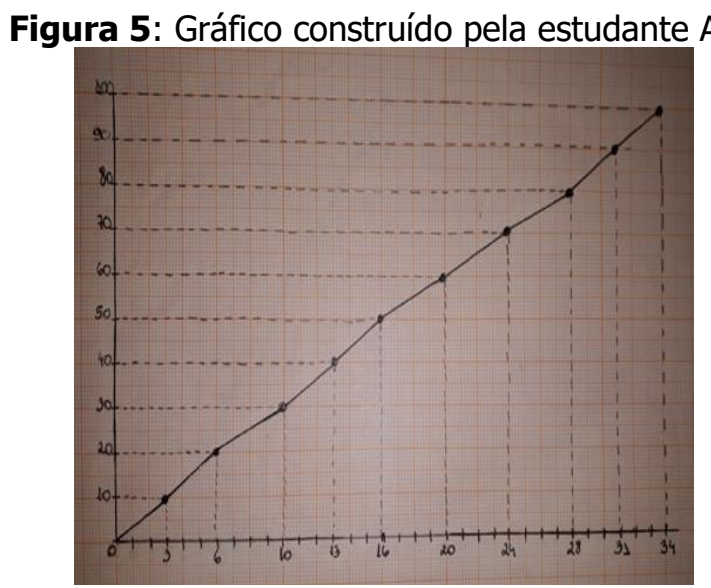

Fonte: acervo do pesquisador

A relação foi percebida pelos estudantes durante as atividades de construção dos gráficos e nos debates que realizamos sobre os gráficos construídos por eles, e em alguns problemas propostos à turma. Dessa forma, mesmo que de forma não explícita, pode-se perceber a formação do conceito de taxa de crescimento do gráfico, os quais, só puderam ser percebidos e interiorizados pelos estudantes por meio do convite que o próprio experimento oportunizou aos mesmos, seja por meio dos erros cometidos ou discussões em grupo, e não de maneira estanque, pronta ou acabada. 
Tal intercâmbio ocorre quando de um lado se tem um sujeito (estudante) atuante, que percorre um caminho em busca das soluções, ou, de maneira análoga, buscando adaptar-se ao objeto e, de outro, o objeto que faz um convite a este percorrer esse caminho. Dessa forma, as referidas trocas ocorrem durante o percurso "trilhado" pelo sujeito, a fim de adaptar-se ao objeto. Esse processo define, segundo a autora citada (LIMA, 1976, p. 15), "o grau de inteligência necessária ao ato". E ainda de acordo com ela:

Em Piaget, a inteligência é, pois, concebida como "a adaptação mental mais avançada", como "a forma de equilíbrio para a qual tendem todas as estruturas, cuja formação deve ser procurada através da percepção, do hábito e dos mecanismos sensório-motores elementares". Assim, em diferentes obras ou em diversos momentos ele reitera a ideia de que os esquemas mentais se derivam dinamicamente uns dos outros, os de agora dos de ontem, os de amanhã dos de hoje, em busca da adaptação e do equilíbrio, que a operação expressa. (LIMA, 1976, p. 15-16)

Tal caminho a que se referem os autores foi percorrido pelos estudantes, e só podemos perceber isso, ou seja, adaptação por parte dos sujeitos (estudantes) em relação ao objeto em estudo, quando eles passam a perceber aspectos peculiares desse objeto. Os reflexos dessa assimilação e adaptação a que se referem os autores são percebidos quando os estudantes criam relações entre a velocidade do experimento e a inclinação dos respectivos gráficos, e também sobre a impossibilidade de o objeto estar em duas posições ao mesmo tempo. Os referidos aspectos podem ser observados a partir das respostas a seguir em que eles, mesmo que implicitamente, constroem conceitos matemáticos.

\section{- Professor: Em quais trechos do gráfico o objeto está mais rápido e em quais está mais devagar?}

- Estudante A.M.: De 0 a 6, de 10 à 16 e de 28 à 34 está mais devagar, pode ver pela reta que está menos "inclinadinho".

A partir da resposta da estudante A.M., é possível afirmar que foi construído pela estudante um conceito importante da matemática, a saber, a taxa de variação do crescimento do gráfico. A seguir, apresentamos à turma um dos gráficos construído pelo estudante M.L. com o propósito de realizar um breve debate no grande grupo. Nessa oportunidade destacamos mais uma vez a necessidade de se tomar cuidado no estabelecimento entre os números no eixo cartesiano, mas também aproveitamos detalhes na construção para a realização da leitura dele. Os referidos detalhes são os triângulos retângulos construídos pelo estudante e que aproveitamos para realizar os seguintes questionamentos.

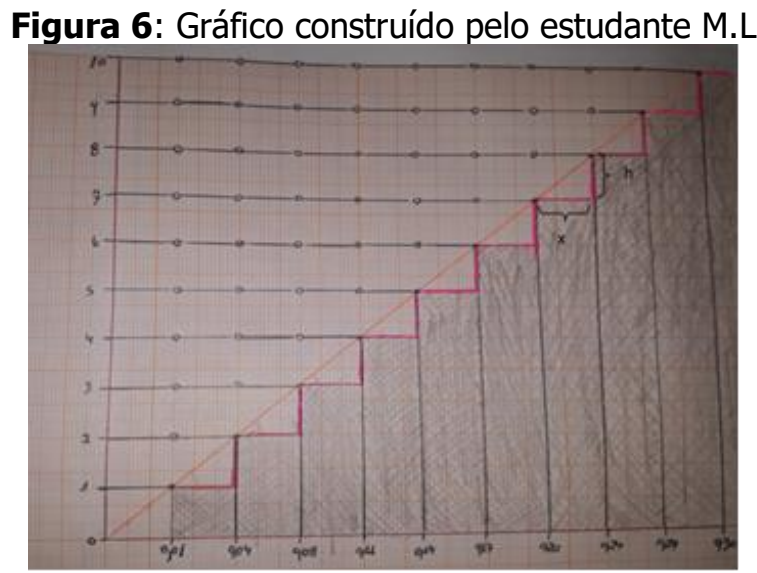

Fonte: acervo do pesquisador 
- Professor: Pessoal, alguém pode me dizer o que o colega fez aqui, o que significa, por exemplo, esse segmento marcado aqui por h? E esse que eu chamei de $x$, o que significa?

- Estudante D.S.: Tu tá falando das bolinhas ou da parte rosa?

- Estudante B.D.: Isso aí é o espaço entre uma distância e outra.

- Professor: Perfeito né, esse é o mesmo segmento situado no eixo y entre 70 e 80 centímetros. Éo espaço percorrido pela moeda na coluna d'água.

- Professor: E a marca denotada por x ali que eu fiz, que marca é essa?

- Estudante B.D.: Essa é a marca exata entre 0,20 e 0,24 segundos.

- Estudante B.D.: Essa é a distância dividida pelo tempo (referindo-se à velocidade da coluna d'água).

A partir dos diálogos realizados no grande grupo em relação aos experimentos anteriores, e as percepções dos estudantes, é possível perceber a construção de conceitos matemáticos presentes nos gráficos em questão e que são citados pelos estudantes. Como pode ser visto na figura 6, há dois gráficos no plano cartesiano, construído por M.L. (gráfico com apoio nos triângulos retângulos) e outro (acima), traçado pelo professor. Nosso objetivo era saber se os estudantes conseguiriam produzir uma leitura desses gráficos relacionando a velocidade de determinados experimentos com a inclinação da reta.

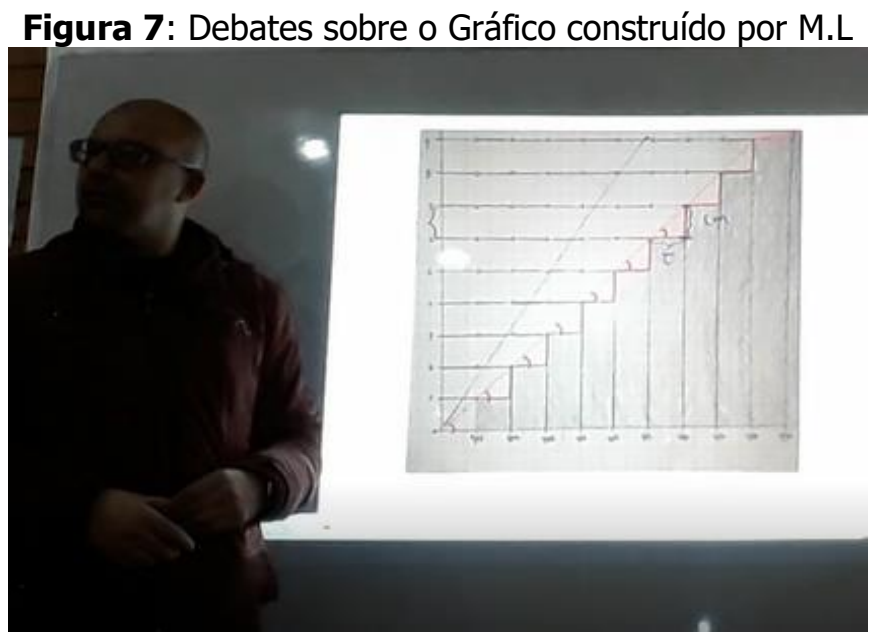

Fonte: acervo do pesquisador

- Professor: Se eu tivesse esses dois gráficos, qual deles é o mais rápido?

- Estudante E.C.: O azul (gráfico de cima).

- Professor: O azul? O azul está mais rápido?

- Estudante B.D.: Com certeza!

- Professor: Por quê?

- Estudante B.D.: Porque a inclinação é maior.

- Professor: Perfeito, porque a inclinação é maior né. Os dois estão certos. 
- Professor: E notem que no gráfico de cima o ponto móvel percorre o mesmo espaço de 90 centímetros em menos tempo. Logo, está mais rápido.

Considera-se importante mencionar aqui que não se está discutindo aqui se os dados coletados pelos estudantes nos experimentos retratam fielmente o experimento observado, já que se trata de uma observação a olho nu de cada um, sujeito a percepção de cada um. Pelo contrário, nosso foco manteve-se na coerência entre a criação e leitura que eles faziam do gráfico relacionado ao experimento.

\section{Experimento 2 (deslocamento de um objeto ao longo de tubo acrílico com água (10 caso)} e glicerina líquida ( $\mathbf{2}^{\circ}$ caso)): Foi proposto aos estudantes a observação de uma esfera e uma moeda percorrendo o tubo acrílico com água, realizados separadamente. Primeiro a moeda percorreu o tubo e depois a esfera. Em seguida, propomos também o mesmo experimento só que agora com glicerina líquida no tubo acrílico, conforme ilustrado na figura 8 a seguir.

Figura 8: Experimento - ponto móvel percorrendo líquido em tubo acrílico

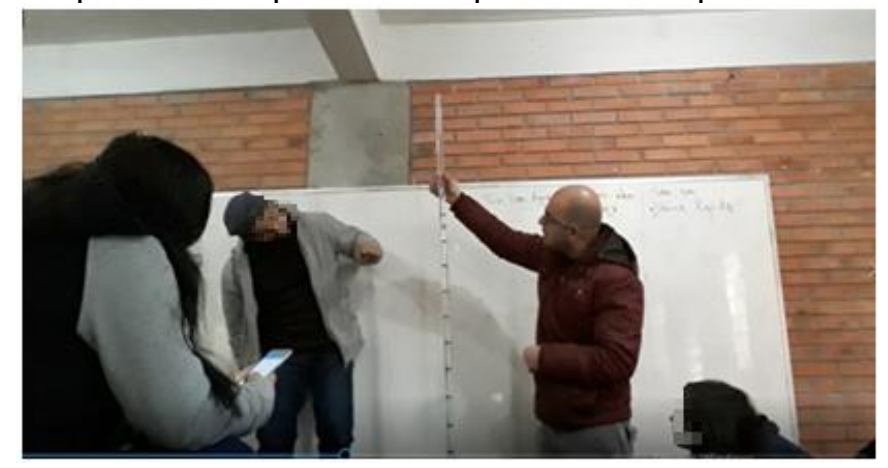

Fonte: acervo do pesquisador

Nossa expectativa com esse experimento era de que os estudantes pudessem perceber características de cada gráfico como, por exemplo, a relação existente entre a velocidade do objeto percorrendo o líquido contido no tubo e as inclinações dos gráficos. Ou seja, a percepção daquilo que chamamos de taxa de variação do gráfico, tal como também estava implícito no primeiro experimento realizado.

Pode-se perceber por meio das construções dos gráficos desse experimento uma coerência nos valores dos eixos e os espaços adotados pelos estudantes na malha quadriculada. Entende-se, dessa forma, que além dos debates realizados em aulas anteriores referentes às construções dos gráficos, um dos fatores que contribuiu para a qualidade dos gráficos foi que o experimento observado oportunizou uma melhor visualização por parte dos estudantes. Tanto pela velocidade em que os objetos percorreram o líquido no tubo quanto pela posição de observação do experimento por parte dos estudantes.

Até que os estudantes chegassem às construções mostradas a seguir, houve experimentos anteriores em que os mesmos cometeram erros como, por exemplo, os espaçamentos em valores nos eixos coordenados, e que por meio de discussões em relação a esses espaçamentos, os quais representam distâncias percorridas dos pontos móveis e os seus respectivos tempos, foi possível construir o gráfico a seguir. Isso possibilitou que os estudantes estabelecessem relações entre aspectos importantes em cada gráfico como, por exemplo, a relação existente entre a inclinação da reta e a velocidade do experimento. Tudo isso pode ser percebido quando as proporções entre as distâncias foram utilizadas coerentemente. 
No gráfico mostrado na figura 9 é possível perceber o cuidado tomado pelos estudantes ao adotarem o mesmo comprimento no "eixo x", o qual representa os tempos observados pelos estudantes. A saber, para cada marca atingida no tubo pela esfera foi definida uma marca de 3,5.

Figura 9: Gráfico construído pelos estudantes N.L. e B.D

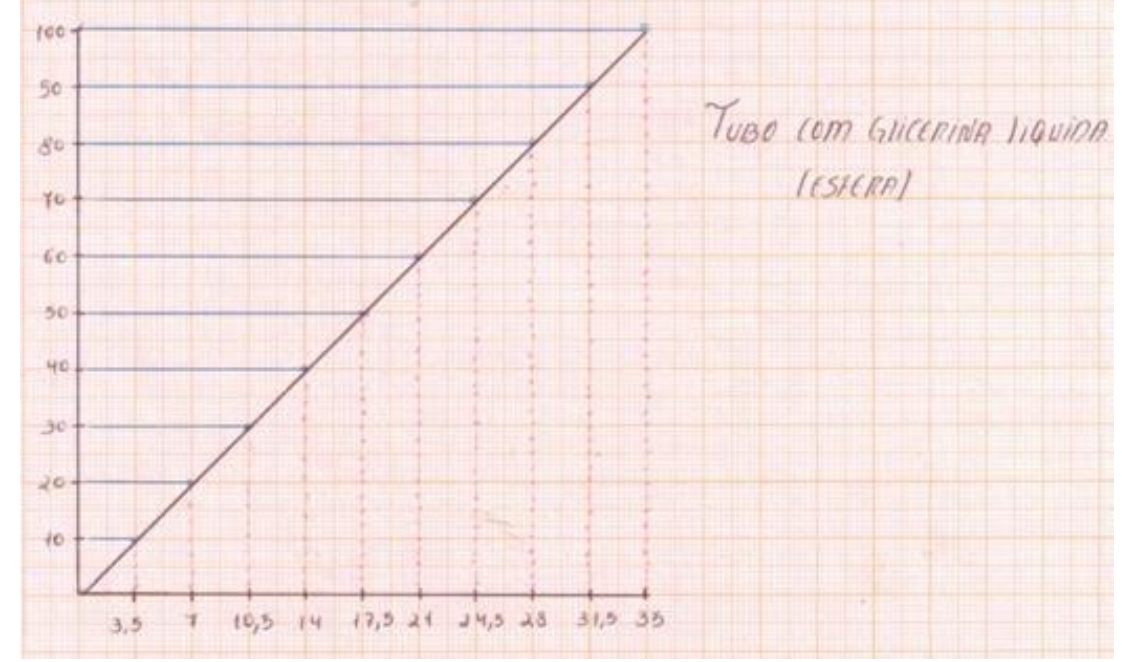

Fonte: acervo do pesquisador

É importante notar, também, a estratégia considerada pelos estudantes para a construção do gráfico acima, uma vez que eles fizeram um arredondamento do tempo para a construção do gráfico. Além disso, também se pode perceber durante a prática o diálogo de alguns deles, relatando que a diferença de tempo entre uma marca e outra atingida pela esfera era sempre o mesmo e que, por isso, a velocidade era constante.

A partir da construção, projetou-se o gráfico na lousa por meio de data show com o propósito de discutirmos sobre aspectos do gráfico construído, conforme diálogo a seguir.

- Professor: pessoal, esse é o experimento com o tubo de glicerina e que, segundo os colegas, as marcas de 10 em 10 centímetros foram atingidas em um intervalo de tempo igual. De 3,5 segundos...

- Estudante M.G.: 3,5 mais 3,5 que vai dá 7.

- Estudante D.S.: Sor, só espaço ali do tempo que ficou um pouquinho maior né?

- Professor: Não, porque eles adotaram pra cada 3,5 de tempo o mesmo espaço no eixo dos tempos.

Também se aproveitou o gráfico construído pelos estudantes (figura 9) para realizar o cálculo da velocidade, a qual foi introduzida a partir daquilo que eles já haviam visto nas placas que limitam a velocidade em vias públicas. Com a seguinte pergunta:

- Professor: quando vemos as placas em vias públicas $80 \mathrm{~km} / \mathrm{h}$, sobre o que isso está se referindo?

- Estudante B.D.: velocidade permitida.

- Professor: mas quando eu digo $80 \mathrm{~km}$ por hora, eu estou dizendo que o veículo está percorrendo $80 \mathrm{~km}$ em uma hora, não é? $80 \mathrm{~km} / \mathrm{h}$ ! 
- Professor: Ou seja, a velocidade é o espaço percorrido em um determinado tempo, ou ainda, 80 $\mathrm{km} / \mathrm{h}=$ (escrito na lousa), que é uma divisão.

- Professor: Então gente, como eu calculo a velocidade nesse gráfico?

- Estudante D.S.: 50 dividido por 17,5?

- Professor: Sim, é uma maneira, teria outra maneira de calcular?

- Estudante A.L.: cinqüenta menos quarenta, dividido por 17,5 menos 14.

- Professor: nesse caso o tempo inicial não é zero né porque eu estou pegando esse trecho entre 40 e 50, se fosse pegar a distância de 50 centímetros aí seria?

- Estudante A.L.: sim.

- Estudante D.S.: 50 menos 40?

- Professor: 50 menos 40, dividido por?

- Estudante A.L.: 3,5 segundos.

É preciso destacar, nesse ponto da discussão, o domínio relativo aos pares ordenados que foi demonstrado pelos estudantes ao relacionar as distâncias percorridas pelo objeto em seus respectivos intervalos de tempo. Tal relação se mostra importante para a realização de uma interpretação adequada do gráfico bem como a determinação de valores importantes que os gráficos fornecem como, por exemplo, a velocidade do objeto, ou, descrevendo matematicamente, a taxa de variação do móvel.

A partir dos valores das distâncias percorridas pelo objeto e os respectivos tempos citados pelos estudantes, calculou-se juntamente à turma a velocidade desse experimento em diversos intervalos de tempo e suas respectivas distâncias.

$$
V m=\frac{50}{17,5}=\frac{50-40}{17,5-14}=\frac{100-60}{35-21}=2,8 \mathrm{~cm} / \mathrm{s}
$$

- Professor: pessoal, se os números dos eixos do gráfico estiverem coerentes em relação a sua proporção e o gráfico for uma reta de fato, o que vai acontecer com a velocidade?

- Estudante A.L.: a velocidade é contínua (quis dizer constante - a mesma em todos os trechos do experimento)

Por meio da participação e reflexão da estudante A.L., em que a mesma conclui que a velocidade é constante, ou seja, é igual em qualquer parte do gráfico, é possível perceber aquilo que David e Lopes (1998, p. 31) chamam de características de estudantes de sucesso em matemática. Pois segundo elas, estes têm capacidade de "[...] generalizar a partir de casos particulares $[. .$.$] ".$

Ademais, é importante trazer novamente ao debate que de maneira alguma se deseja supervalorizar as práticas em detrimento das atividades mentais superiores (educação intelectual). Pois, se entende que quando se utiliza apenas materiais concretos nas aulas de matemática, estejamos assim 
preparando os estudantes apenas para aquilo que é aparente. Quando na verdade, uma das ferramentas que a ciência matemática dispõe ao homem é a de imaginar a partir de experiências e, consequentemente, generalizar a partir delas.

Assim, dentre outros objetivos, o que se buscou foi que os estudantes, a partir de atividades práticas e diálogos em grupo, conseguissem desenvolver as capacidades mentais superiores podendo, assim, fazer generalizações a respeito de determinados fenômenos. Tal capacidade tem a ver com aquilo que Piaget chama de reversibilidade, a qual é definida por Lima (1976, p. 18) como sendo a [...] "capacidade de executar uma mesma ação nos dois sentidos de percurso, mas tendo consciência de que se trata da mesma ação [...]". Segundo ela, isso ocorre no período operatório em que:

O pensamento capta não apenas as realidades físicas aparentes, mas também as suas
transformações. A realidade é vista como um todo permanente, apesar das mudanças
que afetam a percepção. Finalmente no limiar da adolescência o pensamento
consegue sobrepujar a realidade concreta e atingir o mundo das possibilidades.
Surgem as operações formais, alicerçadas no raciocínio hipotético-dedutivo. A
inteligência se liberta do visível, do representável e atinge o seu auge, num equilíbrio
que não quer dizer repouso, mas ajuste das interações. Coincide com a fase
messiânica, em que o adolescente, por uma volta ao egocentrismo, atribui ao seu
pensamento o ilimitado poder de modificar o mundo, reformular valores, consertar a
vida. (LIMA, 1976, p. 18) Assim, percebe-se que por meio da experiência prática, a descrição da mesma, e consequentemente de sua análise, os estudantes puderam realizar constatações a respeito do movimento, formando assim teorias. De modo que, em relação ao movimento em questão, os aprendizes não dependem mais de uma experiência real (concreta) como, por exemplo, descobrir qual o deslocamento do móvel no instante de 3.567 segundos. Não necessitam observar fisicamente essa experiência para concluir que o ponto móvel se deslocou 9.987,6 centímetros, ou 99,876 metros. Parafraseando as palavras de Lima (1976, p. 18), é "o pensamento conseguindo sobrepujar a realidade concreta e atingindo o mundo das possibilidades".

- Professor: a velocidade é contínua, a velocidade é constante, é a mesma velocidade em qualquer trecho do gráfico, vai ser sempre a mesma velocidade.

- Estudante A.L.: movimento uniforme.

- Professor: é um movimento uniforme, exatamente! MU que eles chamam ou MRU que são movimento uniforme ou movimento retilíneo uniforme.

- Estudante D.S.: retilíneo?

- Professor: retilíneo, esses experimentos que estamos fazendo são todos em uma linha reta, pra podermos ter a distância percorrida é melhor, como no tubo acrílico, e por isso é chamado movimento retilíneo.

- Estudante D.S.: professor, por que ele é uniforme?

- Professor: ele é uniforme porque a velocidade não muda, ela é sempre a mesma.

A título de encerramento para os experimentos apresentados, entendemos que seja válido mencionar que o processo que levou os estudantes a realizarem as descobertas acima se deu por meio de uma 
série de experimentos, em que eles coletaram os dados e foram construindo os gráficos relativos a esses experimentos. Ou seja, o conhecimento sendo construído e descoberto a partir da ação deles. $\mathrm{Na}$ verdade, foi nesse sentido que se deu o nosso esforço desde o planejamento das atividades propostas, cujo objetivo era de que os estudantes não recebessem o conhecimento por meio de uma transmissão por parte do professor, em "blocos acabados", mas que por meio da sua própria ação (experiência), fossem observando constatações e inferindo possibilidades.

\section{5. À GUISA DE CONCLUSÕES}

Ao final da pesquisa de mestrado entende-se que a proposta de ateliê de matemática se apresenta como uma alternativa de ensino, que procura valorizar a participação e o modo de pensar dos estudantes em oposição, a um ensino que não oferece oportunidade de construção de conhecimentos pelo estudante. Entende-se dessa forma que o ensino não deva seguir os moldes em que o professor é o elemento ativo da aula e o estudante o passivo, apenas recebendo as noções e conhecimentos prontos. Propõe-se um desenho metodológico de aula em que ambos, professor e estudantes, desempenham um papel ativo na construção de saberes, envolvendo-se no processo de ensinar e aprender. Nas palavras de Castro (1974, p.132), que o "[...] professor esteja tão envolvido no processo quanto o aluno, animando-o a prosseguir, a fazer outras tentativas, e também o desafiando $[\ldots]^{\prime \prime}$.

Ainda se constatou que as atividades proporcionaram aos estudantes desenvolver percepções por meio da experimentação física. Tal experiência faz parte da concepção piagetiana de aprendizagem e, segundo Castro (1974, p. 99), "[...] comporta ações diferenciadas em função dos objetos e consiste em agir sobre eles para descobrir as propriedades que são abstraídas desses próprios objetos. Os resultados da ação estão, nesse caso, vinculados às propriedades do objeto [...]". Portanto, se notou que as atividades de observação direta dos experimentos físicos, bem como a sistematização destes em forma de tabela e plotagem no plano cartesiano, e ainda, o esboço dos gráficos referentes a esses experimentos, contribuíram para que os estudantes abstraíssem e construíssem propriedades do próprio objeto de estudo. Para finalizar, espera-se que a prática aqui exposta mobilize outros professores a levar para a sala de aula formas de trabalho na proposta de um ateliê de matemática, o qual valorize e estimule a participação de todos os partícipes do processo educativo.

\section{REFERÊNCIAS}

ALMEIDA, A. C. Trabalhando matemática financeira em uma sala de aula do ensino médio da escola pública. 2004. Dissertação de Mestrado em Educação. Campinas. SP. 2004.

BORBA, M. C.; ARAÚJO, J. L. Pesquisa qualitativa em educação matemática. Autêntica Editora, 2004.

BRASIL, Ministério da Educação. Base Nacional Comum Curricular (BNCC). Brasília, MEC, CONSED, UNDIME. 2018. Disponível em:

<http://download.basenacionalcomum.mec.gov.br/>. Acesso em: 01/04/2019.

CAMPOS, L. A. Ateliê de matemática: um espaço para diálogo e aprendizagem de matemática no ensino fundamental. 2019. Dissertação de Mestrado em Ensino de Matemática. Universidade Federal do Rio Grande do Sul. 2019. 
CASTRO, A. D. Piaget e a Didática. São Paulo: Saraiva. 1974.

D' AMBRÓSIO, B. Como ensinar matemática hoje? Temas e Debates. Sociedade Brasileira de Educação Matemática (SBEM). Ano II. N2. Brasília. 1989.

D'AMBRÓSIO, U. Prefácio. In: BORBA, M. C.; ARAÚJO, J. L. (Orgs) Pesquisa Qualitativa em Educação Matemática. Belo Horizonte: Autêntica. 2004.

FAZENDA, I. C. A. Interdisciplinaridade: história, teoria e pesquisa. Papirus editora. 1994.

DAVID, M. M. M. S.; LOPES, M. P. Professores que explicitam a utilização de formas de pensamento flexível podem estar contribuindo para o sucesso em matemática de alguns de seus alunos. Zetetiké: Revista de Educação Matemática, v. 6, n. 9, p. 31-58. 1998.

FIORENTINI, D.; LORENZATO, S. Investigação em educação matemática percursos teóricos e metodológicos. Autores Associados. 2006.

JAPIASSU, H. Interdisciplinaridade e patologia do saber. Imago Editora. 1976.

LIMA, B. B. Linguagem e pensamento em Piaget: consequências metodológicas para o ensino de línguas. Editora Vozes. 1976.

LOPES, J.; ANGOTTI, J.; MORETTI, M. T. Função afim e Conceitos Unificadores: o ensino de Matemática e Física numa Perspectiva Conceitual e Unificadora.In: IV ENPEC (Encontro Nacional de Pesquisa em Ensino de Ciências). 2003.

PIAGET, J. Para onde vai a educação? Tradução: BRAGA, I. J. Olympio. 2011.

PIETROCOLA, M. A matemática como estruturante do conhecimento físico. Caderno brasileiro de ensino de física, v. 19, n. 1, p. 93-114. 2002. 